Research Article

\title{
Protective and Blast Resistive Design of Posttensioned Box Girders Using Computational Geometry
}

\author{
Majid Aleyaasin (iD) \\ School of Engineering, University of Aberdeen, Fraser Noble Building, Aberdeen AB24 3UE, UK \\ Correspondence should be addressed to Majid Aleyaasin; eng780@abdn.ac.uk
}

Received 16 August 2017; Revised 21 November 2017; Accepted 6 December 2017; Published 22 February 2018

Academic Editor: Lucia Figuli

Copyright (C) 2018 Majid Aleyaasin. This is an open access article distributed under the Creative Commons Attribution License, which permits unrestricted use, distribution, and reproduction in any medium, provided the original work is properly cited.

\begin{abstract}
The optimal tendon profile and its associated duct geometry for posttensioned box girders are investigated. A computational algorithm has been developed to determine an ideal shape for the tendon and duct. The algorithm is based on a diagonal cross point in the Magnel quadrilateral and uses computational geometry instead of graphical drawing. Thereafter, an ideal parabolic and linear tendon profiles can be calculated from which the covering duct could be shaped. To check the optimality of the results, an automatic examination of Magnel diagrams in various cross sections is incorporated in the algorithm. This enables a unique prestress level to be selected that suits all sections. Then, the mideccentricity of the two crossing points with a common prestress line is chosen as a design eccentricity in each cross section. The optimal duct shape is determined based on such automatic inspections. In a numerical example, the linear, parabolic, and optimal duct geometries are compared and drawn. It is concluded that both linear and parabolic duct shapes can be very close to an optimal shape. In a numerical example, an optimal, box girder with linear open access-type tendons is designed that can withstand extra blast load when explosion occurs.
\end{abstract}

\section{Introduction}

Steel is used in concrete bridges as a reinforcement material. Therefore, the protection against corrosion for increasing lifetime of the bridge is an important issue and remains an active field of research [1]. Advanced methods for protection needs accessibility inside the box girder as described in [2]. A suitable open access type to the prestressed tendons is open linear duct type as shown in Figure 1 [3]. In this scheme, tendons are accessible easily and can be monitored continuously.

It is obvious that the accessibility to the steel tendon as shown in Figure 1 is superior to other types of design. This will be useful particularly when inspection for corrosion and crack protection is required. The corrosion protection in precast bridges is a formidable task as explained in [4]. Therefore, open access posttensioned segments similar to Figure 1 are corrosion and also crack protective.

Recently, protection of the bridges against explosions due to, for example, car bombs is studied seriously, and one of the damages is shown in Figure 2. The permanent deformation is caused by immediate microcracks just after explosion [5]. The author believes that the open access design shown in Figure 1 can also be blast protective because it can be optimised to take the extra blast load as it is shown in a numerical example in this paper. Moreover, the possible cracks after explosions can be inspected much easier.

Regarding the extra blast load, the bomb power or explosive amount (equivalent TNT mass) and also the distance between the explosion centre and the bridge are required. Then, we need to find the scaled distance from the following equation:

$$
Z=\frac{R}{M_{\mathrm{TNT}}^{1 / 3}} .
$$

Then, the resulting overpressure (in $\mathrm{kPa}$ ) due to the explosion [6] is

$$
p=912.88 Z^{-1.46635} .
$$

Then, the extra blast load is $W_{\mathrm{ex}}=p b$ ( $b$ is the width of the bridge).

This paper provides a new method that is suitable for the optimal design of an accessible linear-type, posttensioned 


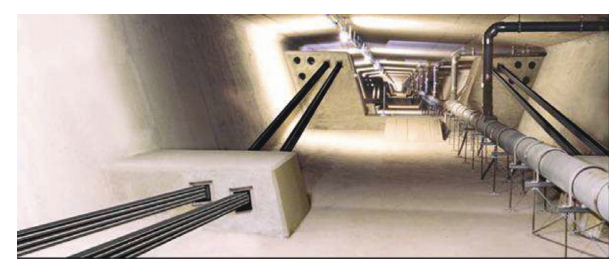

(a)

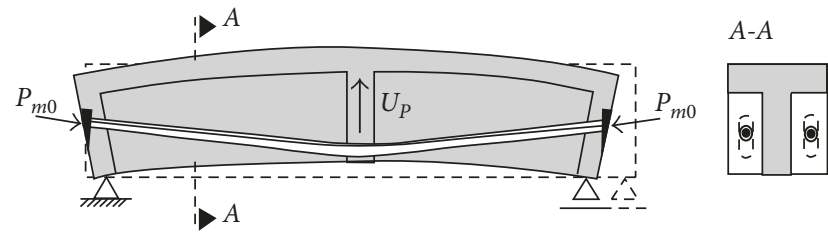

(b)

FIgURE 1: (a) Externally posttensioned: inside of box girder cross section. (b) Externally posttensioned beam: girder outside web.

tendon and its duct. The method is based on the traditional Magnel diagram [7], but its novelty is the combination with computational geometry, by which an algebraic computerised algorithm can be developed.

There are two types of prestressed concrete members. In pretensioned type, the strands are pretensioned before casting, and then it is essential that the prestress level in various cross sections should be different. In order to achieve this objective, debonding technology is adopted by which some strands are partially debonded from concrete [7]. This article is not related to pretensioned beams since the majority of box girders are built via posttensioned members.

However, in posttensioned beams and members, the prestress level in all cross sections is similar. The tensioning is planned after casting; therefore, the tendons are not straight and can be covered in a curved duct [8]. There are various methods for determination of the ideal tendon and duct profile; for example, the criteria in [8] are different from the one in [9]. In order to obtain an accurate profile, "design curves" are introduced in [10] by which in any cross section the suitable eccentricity is determined by the design curve and finally the profile could be built.

Since an ideal tendon profile determination is a design problem, it should be noted that the designers have been using a graphical design method which was developed by Magnel [11] in late forties. Since then, the Magnel design diagram has been revisited in [12], and the edges of the Magnel quadrilateral are specified as criteria for choosing an appropriate eccentricity and prestress level. Recently, Calladine [13] has used the mapping technique and converted the Magnel quadrilateral to a parallelogram by which the design procedure becomes easier. Moreover, Stanton [14] introduced a simple sign convention in order to draw the Magnel diagram by one equation only.

In this article, it is shown that the ideal tendon profile in the posttensioned beam could be determined by automated computer inspection of the Magnel diagrams, in the various cross sections without drawing any quadrilateral on paper. By using computational geometry, first the coordinates of the edges of the Magnel quadrilateral is calculated. Then, the

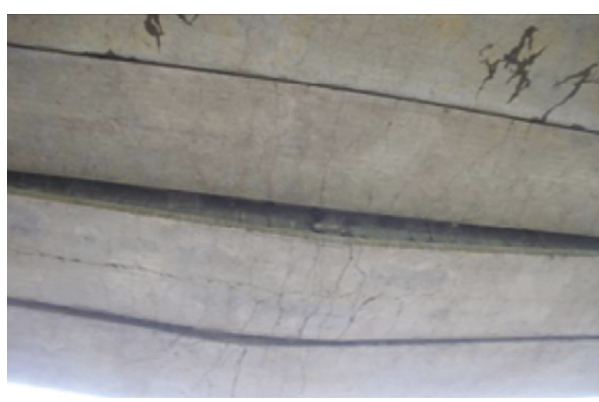

FIgure 2: Permanent deformation of box girder after explosion.

coordinates of the crossing points of the two diagonals of the quadrilateral in the cross section in which maximum service bending moment occurs is determined. Similar procedure is repeated for two more cross sections, and thereby a parabolic or linear curve could be computed, knowing three eccentricities across the beam span. Further investigation is carried out to show the accuracy of this type of design.

In a numerical example for a long span box girder bridge, by examining the Magnel quadrilateral in many more cross sections and considering a prestress level that suits all the cross sections, the corresponding eccentricities are computed and a smooth curve is fitted to all the points. When comparing this optimal duct shape with the parabolic and linear ones, it does not show any significant difference.

The whole drawing process and inspection and selection are algorithmic and can be done via one computer program. It is shown that we can determine the ideal parabolic and linear duct shapes and also check their closeness to optimal duct shape, all in one algorithm. It is concluded that both parabolic and linear duct geometries introduced in this paper are simple and optimal. Therefore, we can choose an accessible and easily protectable linear tendons and duct shape which is also an optimal design. The method is based on automatic inspection of the Magnel diagram and particularly can be useful for checking the Magnel polygon in the cross section where the deviator is located and sharp changes (discontinuities) in prestress occur.

\section{Magnel Design Diagram}

The top fibres of a beam in transfer (before service) are in tension since the beam planned to be in hogging, and if the allowable tensile transfer stress is $f_{\mathrm{tt}} \leq 0$, then the stress constraint would be

$$
\sigma=\frac{M_{T}}{Z_{T}}+\frac{P}{A}+\frac{P e}{Z_{T}} \geq f_{\mathrm{tt}} .
$$

In (3), $\sigma>f_{\mathrm{tt}}$ while $|\sigma|<\left|f_{\mathrm{tt}}\right|$ because in the transfer state, the top fibres are in tension ( - sign by convention) and then $f_{\mathrm{tt}} \leq 0$ also $Z_{t}>0, P>0, M_{t}>0$, and $e<0$. Manipulating (3) leads to the following inequality:

$$
\frac{1}{P} \geq \frac{e}{f_{\mathrm{tt}} Z_{t}-M_{t}}+\frac{Z_{t}}{A Z_{t} f_{\mathrm{tt}}-A M_{t}} .
$$

The bottom fibres of a beam in transfer, when it is in hogging, are in compression, and if the allowable 
compressive transfer stress is $f_{\mathrm{tc}} \geq 0$, then the stress constraint would be

$$
\sigma=\frac{M_{t}}{Z_{b}}+\frac{P}{A}+\frac{P e}{Z_{b}} \leq f_{\mathrm{tc}}
$$

In (5), $\sigma<f_{\text {tc }}$ while $|\sigma|<\left|f_{\text {tc }}\right|$ because in the transfer state, bottom fibres are in compression (+ sign by convention) and then $f_{\mathrm{tc}}>0$ also $Z_{b}<0, P>0, M_{t}>0$, and $e<0$. Manipulating (5) leads to the following inequality:

$$
\frac{1}{P} \geq \frac{e}{f_{\mathrm{tc}} Z_{b}-M_{t}}+\frac{Z_{t}}{A Z_{b} f_{\mathrm{tc}}-A M_{t}} .
$$

The top fibres of a beam in service obviously are in compression because the beam is in sagging, and if the allowable compressive service stress is $f_{\mathrm{sc}} \geq 0$, then the stress constraint would be

$$
\sigma=\frac{M_{s}}{Z_{t}}+\frac{\alpha P}{A}+\frac{\alpha P e}{Z_{t}} \leq f_{\mathrm{sc}} .
$$

In (7), $\sigma<f_{\text {sc }}$ while $|\sigma|<\left|f_{\text {sc }}\right|$ because in the service state, top fibres are in compression ( + sign by convention); so $f_{\mathrm{sc}}>0$ also $Z_{t}>0, P>0, M_{s}>0$, and $e<0$. Parameter $0 \leq \alpha \leq 1$ represents the minimum conserved prestress factor in service since during service prestress level would be lost [8] and $(1-\alpha)$ expresses this maximum loss. Now, by manipulating (7), the following inequality would be obtained:

$$
\frac{1}{P} \geq \frac{\alpha e}{f_{\mathrm{sc}} Z_{t}-M_{s}}+\frac{\alpha Z_{t}}{A Z_{t} f_{\mathrm{sc}}-A M_{s}}
$$

The bottom fibres of a beam in service (sagging) are in tension, and if the allowable tensile service stress is $f_{\mathrm{st}} \leq 0$, then the stress constraint would be

$$
\sigma=\frac{M_{s}}{Z_{b}}+\frac{\alpha P}{A}+\frac{\alpha P e}{Z_{b}} \leq f_{\mathrm{st}} .
$$

In (9), $0 \leq \alpha \leq 1$ appears again because of service condition. $\sigma>f_{\text {st }}$ while $|\sigma|<\left|f_{\text {st }}\right|$ because in the service state, bottom fibres are in tension (- sign by convention), so $f_{\text {st }} \leq 0$ also $Z_{b}<0, P>0, M_{s}>0$, and $e<0$. By manipulating (9), the following inequality would be obtained:

$$
\frac{1}{P} \leq \frac{\alpha e}{f_{\mathrm{st}} Z_{b}-M_{s}}+\frac{\alpha Z_{b}}{A Z_{b} f_{\mathrm{st}}-A M_{s}} .
$$

The four stress constraints (3), (5), (7), and (9) lead to the inequalities (4), (6), (8), and (10) in a coordinate system in which $e$ is the horizontal axis and $\left(P^{-1}\right)$ is the vertical axis. The borders of these four inequalities are designated by four lines, and when they cross each other, they form a quadrilateral in which the design parameters $e$ and $\left(P^{-1}\right)$ are chosen from inside of this quadrilateral. Overall design diagram was first introduced by Magnel [11] and has been used by designers ever since $[7,8]$. Obviously, in various types of prestress losses and for this reason for design purposes, the minimum conservation (maximum loss) should be considered.
In Section 3, we will show that, by symbolic computation of the four edges in the Magnel quadrilateral, we can seek inside the region to find an appropriate design point for each cross section. First, parabolic and linear tendon profiles will be derived by using three cross sections. Thereafter, an algorithm for an ideal tendon profile will be explained by using several cross sections. In a numerical example, it will be shown that parabolic and linear profiles are very close to the ideal profile.

\section{New Algorithm for Computation of Tendon Profile}

The borderlines of the constraints for $f_{\mathrm{tt}}$ in (4) and $f_{\mathrm{tc}}$ in (6) cross each other in the edge designated by coordinates $(e)_{\mathrm{t}-\mathrm{tc}}$ and $\left(P^{-1}\right)_{\mathrm{t} \mathrm{t}-\mathrm{tc}}$ as follows:

$$
\begin{aligned}
(e)_{\mathrm{tt}-\mathrm{tc}} & =\frac{\left(Z_{t} f_{\mathrm{tt}}-M_{t}\right) Z_{b}-\left(Z_{b} f_{\mathrm{tc}}-M_{t}\right) Z_{t}}{\left(Z_{b} f_{\mathrm{tc}}-M_{t}\right) A-\left(Z_{t} f_{\mathrm{tt}}-M_{t}\right) A}, \\
\left(P^{-1}\right)_{\mathrm{tt}-\mathrm{tc}} & =\frac{(e)_{\mathrm{tt}-\mathrm{tc}} A-Z_{t}}{\left(Z_{t} f_{\mathrm{tt}}-M_{t}\right) A} .
\end{aligned}
$$

The borderlines of the constraints for $f_{\mathrm{st}}$ in (10) and $f_{\mathrm{sc}}$ in (8) cross each other in the edge designated by coordinates $(e)_{\text {st-sc }}$ and $\left(P^{-1}\right)_{\text {st-sc }}$ as follows:

$$
\begin{aligned}
(e)_{\mathrm{st}-\mathrm{sc}} & =\frac{\left(Z_{b} f_{\mathrm{st}}-M_{s}\right) Z_{t}-\left(Z_{t} f_{\mathrm{sc}}-M_{s}\right) Z_{b}}{\left(Z_{t} f_{\mathrm{sc}}-M_{s}\right) A-\left(Z_{b} f_{\mathrm{st}}-M_{s}\right) A}, \\
\left(P^{-1}\right)_{\mathrm{st}-\mathrm{sc}} & =\frac{\left((e)_{\mathrm{st}-\mathrm{sc}} A+Z_{b}\right) \alpha}{\left(Z_{b} f_{\mathrm{st}}-M_{s}\right) A} .
\end{aligned}
$$

The borderlines of the constraints for $f_{\text {st }}$ in (10) and $f_{\mathrm{tt}}$ in (4) cross each other in the edge designated by coordinates $(e)_{\text {st- } t \mathrm{t}}$ and $\left(P^{-1}\right)_{\mathrm{st}-\mathrm{tt}}$ as follows:

$$
\begin{aligned}
(e)_{\mathrm{st}-\mathrm{tt}} & =\frac{\left(Z_{b} f_{\mathrm{st}}-M_{s}\right) Z_{t}-\left(Z_{t} f_{\mathrm{tt}}-M_{t}\right) \alpha Z_{b}}{\left(Z_{t} f_{\mathrm{tt}}-M_{t}\right) \alpha A-\left(Z_{b} f_{\mathrm{st}}-M_{s}\right) A} \\
\left(P^{-1}\right)_{\mathrm{st}-\mathrm{tt}} & =\frac{(e)_{\mathrm{st}-\mathrm{tt}} A-Z_{t}}{\left(Z_{t} f_{\mathrm{tt}}-M_{t}\right) A} .
\end{aligned}
$$

The borderlines of the constraints for $f_{\mathrm{sc}}$ in (8) and $f_{\mathrm{tc}}$ in (6) cross each other in the edge designated by coordinates $(e)_{\mathrm{sc}-\mathrm{tc}}$ and $\left(P^{-1}\right)_{\mathrm{sc}-\mathrm{tc}}$ as follows:

$$
\begin{aligned}
(e)_{\mathrm{st}-\mathrm{tc}} & =\frac{\left(Z_{t} f_{\mathrm{sc}}-M_{s}\right) Z_{b}-\left(Z_{b} f_{\mathrm{tc}}-M_{t}\right) \alpha Z_{t}}{\left(Z_{b} f_{\mathrm{tc}}-M_{t}\right) \alpha A-\left(Z_{t} f_{\mathrm{sc}}-M_{s}\right) A}, \\
\left(P^{-1}\right)_{\mathrm{sc}-\mathrm{tc}} & =\frac{(e)_{\mathrm{sc}-\mathrm{tc}} A+Z_{t}}{\left(Z_{b} f_{\mathrm{tc}}-M_{t}\right) A} .
\end{aligned}
$$

The edge with the coordinates $(e)_{\text {st- tt }}$ and $\left(P^{-1}\right)_{\text {st-tt }}$ is opposite to the edge with the coordinates $(e)_{\mathrm{sc}-\mathrm{tc}}$ and $\left(P^{-1}\right)_{\text {sc-tc }}$. Connecting these two edges provides a diagonal with the following slope:

$$
(m)_{\mathrm{sc}-\mathrm{tc}}^{\mathrm{st}-\mathrm{tt}}=\frac{\left(P^{-1}\right)_{\mathrm{st}-\mathrm{tt}}-\left(P^{-1}\right)_{\mathrm{sc}-\mathrm{tc}}}{(e)_{\mathrm{st}-\mathrm{tt}}-(e)_{\mathrm{sc}-\mathrm{tc}}},
$$


and the corresponding line can be expressed by the following equation:

$$
\left(P^{-1}\right)-\left(P^{-1}\right)_{\mathrm{st}-\mathrm{tt}}=\left((e)-(e)_{\mathrm{st}-\mathrm{tt}}\right)(m)_{\mathrm{sc}-\mathrm{tc}}^{\mathrm{st} \cdot \mathrm{tt}}
$$

The edge with the coordinates $(e)_{\mathrm{tt}-\mathrm{tc}}$ and $\left(P^{-1}\right)_{\mathrm{tt}-\mathrm{tc}}$ is opposite to the edge with the coordinates $(e)_{\text {st-sc }}$ and $\left(P^{-1}\right)_{\text {st-sc }}$. Connecting these two edges provides a diagonal with the following slope:

$$
(m)_{\mathrm{st}-\mathrm{tc}}^{\mathrm{tt}-\mathrm{sc}}=\frac{\left(P^{-1}\right)_{\mathrm{tt}-\mathrm{tc}}-\left(P^{-1}\right)_{\mathrm{st}-\mathrm{sc}}}{(e)_{\mathrm{tt}-\mathrm{tc}}-(e)_{\mathrm{st}-\mathrm{sc}}}
$$

and corresponding line can be expressed by the following equation:

$$
\left(P^{-1}\right)-\left(P^{-1}\right)_{\mathrm{tt}-\mathrm{tc}}=\left((e)-(e)_{\mathrm{tt}-\mathrm{tc}}\right)(m)_{\mathrm{st}-\mathrm{tc}}^{\mathrm{tt}-\mathrm{sc}} .
$$

Intersection of the lines (16) and (18) represents the centre of the quadrilateral which possesses the eccentricity $e_{\mathrm{DM}}$ and can be calculated by

$e_{\mathrm{DM}}=\frac{\left(P^{-1}\right)_{\mathrm{tt}-\mathrm{tc}}-\left(P^{-1}\right)_{\mathrm{st}-\mathrm{tt}}+(m)_{\mathrm{st}-\mathrm{tc}}^{\mathrm{st}-\mathrm{tt}}(e)_{\mathrm{st}-\mathrm{tt}}-(m)_{\mathrm{st}-\mathrm{sc}}^{\mathrm{tt}-\mathrm{sc}}(e)_{\mathrm{tt}-\mathrm{tc}}}{(m)_{\mathrm{st}-\mathrm{tc}}^{\mathrm{st}}-(m)_{\mathrm{st}-\mathrm{sc}}^{\mathrm{tt}-\mathrm{sc}}}$.

Similarly, we can calculate $e_{\mathrm{DM}}$ in two other cross sections to obtain parabolic and linear curves. For example, in a simply supported beam with span $L$, the maximum bending moment occurs in middle span $0.5 \mathrm{~L}$, the other two cross sections could be at the supporting ends, and their corresponding eccentricity $e_{\mathrm{DC}}$ can be calculated from (19) by substituting $M_{t}=0$ and $M_{s}=0$, that is,

$$
e_{\mathrm{DC}}=\left.e_{\mathrm{DM}}\right|_{M_{s}=M_{t}=0} \text {. }
$$

Since at $x=0.5 L$, the eccentricity is $e(0.5 L)=e_{\mathrm{DM}}$ and in the supports $e(L)=e(0)=e_{\mathrm{DC}}$, and then an ideal parabolic tendon profile could be computed by

$$
e(x)=4\left(e_{\mathrm{DM}}-e_{\mathrm{DC}}\right)\left(\frac{x}{L}-\frac{x^{2}}{L^{2}}\right)+e_{\mathrm{DC}} .
$$

And for linear tendon profile similar to Figure 1, we have

$$
\begin{aligned}
& e(x)=2\left(e_{\mathrm{DM}}-e_{\mathrm{DC}}\right) \frac{x}{L}+e_{\mathrm{DC}}, \quad 0 \leq x \leq \frac{L}{2}, \\
& e(x)=2\left(e_{\mathrm{DM}}-e_{\mathrm{DC}}\right)\left(1-\frac{x}{L}\right)+e_{\mathrm{DC}}, \quad \frac{L}{2} \leq x \leq L .
\end{aligned}
$$

Another ideal tendon profile can also be achieved, if the Magnel diagram would be drawn in many cross sections $(n>3)$, across the span. This is a formidable task for a designer, but can be programmed easily by a computer. Then, for every Magnel quadrilateral, we have a pair of diagonals with equations

$$
\begin{aligned}
& \left(P^{-1}\right)-\left(P_{i}^{-1}\right)_{\mathrm{st}-\mathrm{tt}}=\left((e)-\left(e_{i}\right)_{\mathrm{st}-\mathrm{tt}}\right)\left(m_{i}\right)_{\mathrm{sc}-\mathrm{tc},}^{\mathrm{st}-\mathrm{tt}} \quad i=1,2, \ldots, n \\
& \left(P^{-1}\right)-\left(P_{i}^{-1}\right)_{\mathrm{tt}-\mathrm{tc}}=\left((e)-\left(e_{i}\right)_{\mathrm{tt}-\mathrm{tc}}\right)\left(m_{i}\right)_{\mathrm{st}-\mathrm{sc}}^{\mathrm{tt}-\mathrm{tc}}, i=1,2, \ldots, n
\end{aligned}
$$

By simple visual inspection of all diagrams in one figure, it is very easy to check which prestress level suits all the quadrilaterals in the figure. This inspection is also possible without any drawing and can be done by intelligent computer searching. When a design prestress level was selected and named $\left(P^{-1}\right)_{D}$, by its substitution into (24) and (25), two candidates for the eccentricity in each cross section can be found via the following formulas:

$$
\begin{aligned}
& \left(e_{i}\right)_{C 1}=\frac{\left(P^{-1}\right)_{D}-\left(P_{i}^{-1}\right)_{\mathrm{st}-\mathrm{tt}}}{\left(m_{i}\right)_{\mathrm{sc}-\mathrm{tc}}^{\mathrm{st}}}+\left(e_{i}\right)_{\mathrm{st}-\mathrm{tt} \mathrm{t}} \quad i=1,2, \ldots, n, \\
& \left(e_{i}\right)_{\mathrm{C} 2}=\frac{\left(P^{-1}\right)_{D}-\left(P_{i}^{-1}\right)_{\mathrm{tt}-\mathrm{tc}}}{\left(m_{i}\right)_{\mathrm{st}-\mathrm{sc}}^{\mathrm{t}-\mathrm{sc}}}+\left(e_{i}\right)_{\mathrm{tt}-\mathrm{tc}}, \quad i=1,2, \ldots, n .
\end{aligned}
$$

To be on the conservative side, the average of the above could be considered as the design eccentricity for each cross section, that is,

$$
\left(e_{i}\right)_{D}=0.5\left(\left(e_{i}\right)_{C 1}+\left(e_{i}\right)_{C 2}\right), \quad i=1,2, \ldots, n .
$$

\section{Numerical Example}

The numerical example is taken from [12]. The prestressed beam, simply supported at the ends with the cross section $A=0.3045 \mathrm{~m}^{2}$, has the span $L=18.3 \mathrm{~m}$, the width $b=1.22 \mathrm{~m}$, the height $h=0.61 \mathrm{~m}$, and the section modulus $Z_{t}=0.0352 \mathrm{~m}^{3}$ and $Z_{b}=-0.03869 \mathrm{~m}^{3}$; the limit stresses are $f_{\mathrm{tt}}=-1.34 \mathrm{MPa}$, $f_{\mathrm{tc}}=17.38 \mathrm{MPa}, f_{\mathrm{sc}}=18.6 \mathrm{MPa}$, and $f_{\mathrm{st}}=-3.21 \mathrm{MPa}$; the dead weight is $W_{t}=8.76 \mathrm{kN} / \mathrm{m}$; and $500 \mathrm{~kg}$ of TNT exploded $200 \mathrm{~m}$ away from the bridge while traffic load $W_{\mathrm{tr}}=5.5 \mathrm{kN} / \mathrm{m}$ in service condition should be considered. The prestress loss is expressed by the parameter $\alpha=0.8$. We need to find the optimal duct shape and the eccentricities as shown in Figure 1 and displayed in [3].

The scaled distance of this explosion will be considered as a part of service load:

$$
Z=\frac{R}{M_{\mathrm{TNT}}^{1 / 3}}=\frac{200}{500^{1 / 3}}=25.1984 \mathrm{~m} / \mathrm{kg}^{1 / 3} .
$$

The resulting overpressure (in $\mathrm{kPa}$ ) due to the explosion is

$$
p=912.88 Z^{-1.46635}=912.88 \times 25.1984^{-1.46635}=8.045 \mathrm{kPa} \text {. }
$$

This produces overpressure load as a result of explosion:

$$
\begin{aligned}
& W_{\mathrm{ex}}=p b=8.045 \times 1.22=9.815 \mathrm{kN} / \mathrm{m}, \\
& W_{a}=W_{\mathrm{ex}}+W_{\mathrm{tr}}=(9.815+5.5)=15.32 \mathrm{kN} / \mathrm{m} .
\end{aligned}
$$

The maximum transfer bending moment occurring at a midspan is

$$
M_{t}=\frac{W_{t} L^{2}}{8}=\frac{8.76 \times 18.3^{2}}{8}=366.1 \mathrm{kN} \cdot \mathrm{m} .
$$




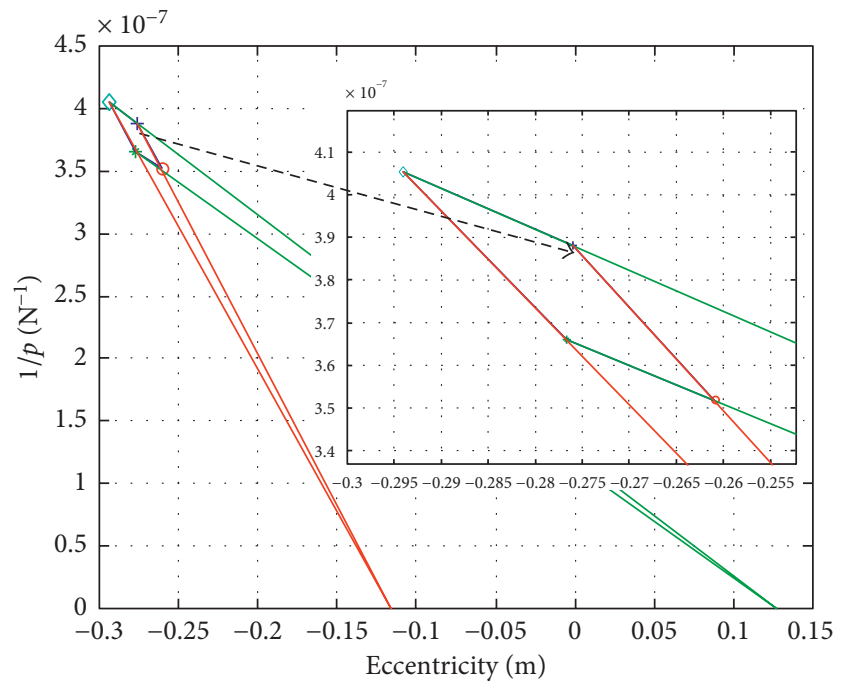

Figure 3: Magnel design diagram in the midspan cross section.

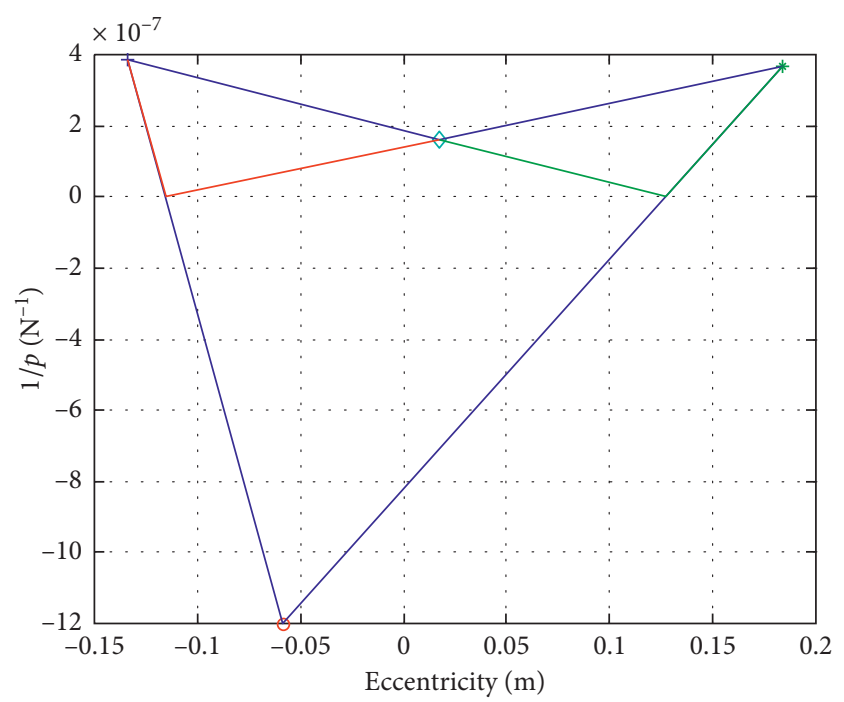

Figure 4: Magnel design diagram in the supporting ends.

The maximum transfer bending moment occurring at a midspan is

$$
\begin{aligned}
M_{t}=\frac{\left(W_{t}+W_{a}\right) L^{2}}{8} & =\frac{(8.76+15.32) \times 18.3^{2}}{8} \\
& =1006.8 \mathrm{kN} \cdot \mathrm{m}
\end{aligned}
$$

The Magnel diagram in the maximum bending moment cross section is drawn in Figure 3; the quadrilateral occupies a small region in the coordinate system, and for the designer, it is difficult to spot the centre, and the quadrilateral has been magnified in the figure.

In Figure 4, the design diagram is drawn at the ends, in which both the transfer moment $M_{t}=0$ and service moment $M_{s}=0$, we can see that the relevant quadrilateral occupies much larger region in the coordinate system plane. Although the quadrilateral losses its convexity, the centre of it is still

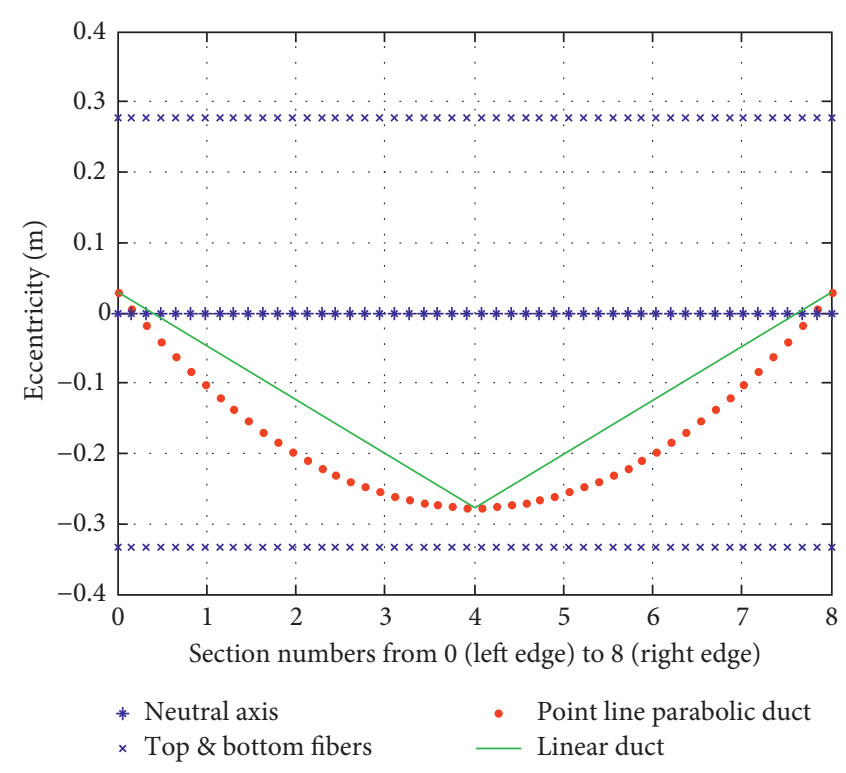

FIgUre 5: Position of the tendon, neutral axis, and top and bottom fibres across the span.

an appropriate design point. One can see that the design point will be outside the quadrilateral, but its eccentricity coordinate is in the acceptable range. The designer finally will choose a prestress level which suits all cross sections.

Based on (19) and (20), parabolic and linear tendons are designed, and the position of the strand, relative to the neutral axis in each cross section, is shown in Figure 5. The neutral axis represents zero eccentricity and is shown by dash ${ }^{*}$ line; sign $\times$ represents top and bottom fibres. The linear strand position is shown by the solid line, and the point line shows the parabolic strand.

In order to see if these types of tendon profiles are accurate enough, we will draw the Magnel diagram in nine cross sections each with $L / 8$ apart. Because of symmetry, we need only five Magnel diagrams, which all are drawn in Figure 6. Although we have plotted each diagram in separate figure, it is difficult to compare all quadrilaterals. However, it is easy to find out that a prestress level equal to the average of prestresses at edges of the quadrilateral of the midspan is an appropriate criterion. The horizontal line corresponding to this prestress level intersects all Magnel quadrilaterals.

This enabled (26)-(28) to be used, and in each cross section, $\left(e_{i}\right)_{D}$ could be computed. Using $\left(e_{i}\right)_{D}$, which resulted in nine points, by which a symmetric curve is produced and the tendon profile is displayed in Figure 7 by the point line, one can see that the simple linear profile in Figures 1(a) and 5 and the optimal profile in Figure 7 are very close, and in fact the parabolic and linear shape tendons can be ideal ones, if we use the expressions in (21)-(23) in this paper.

\section{Conclusions}

In this article, the ideal tendon profile in the posttensioned beams is investigated by multiple automatic examinations of the Magnel design diagrams. An algorithm was introduced by which one can calculate ideal parabolic and linear tendon 


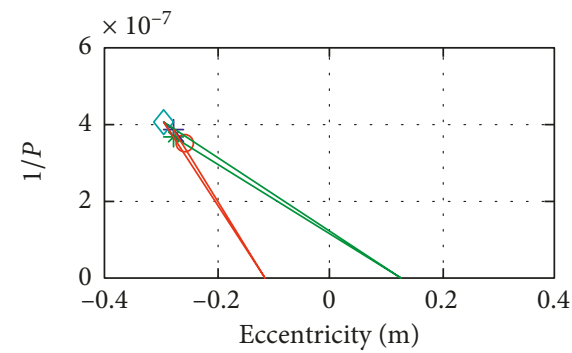

(a)

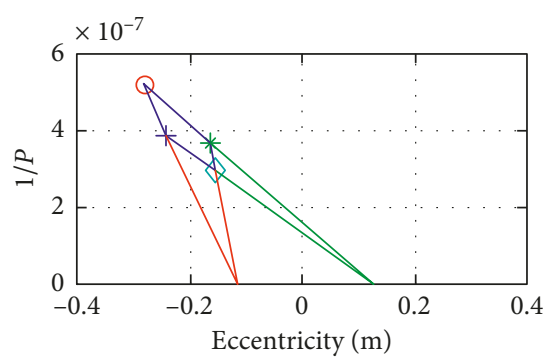

(b)

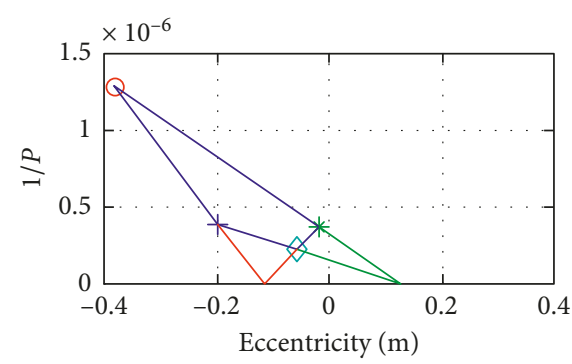

(c)

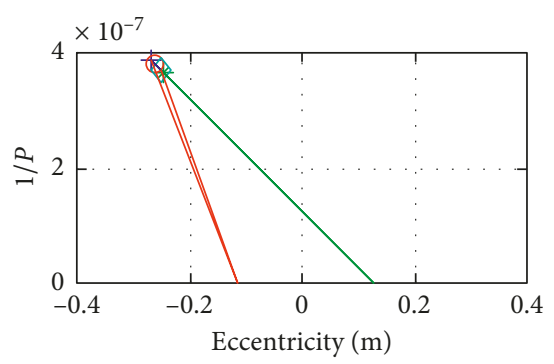

(d)

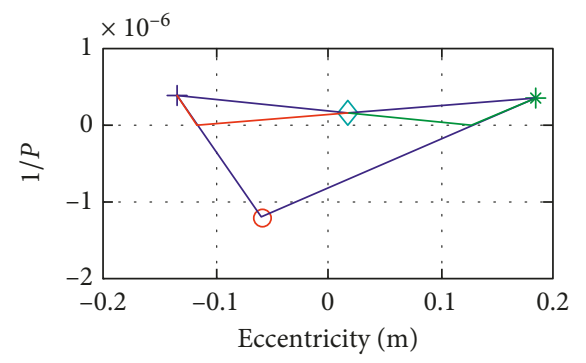

(e)

Figure 6: Magnel diagrams for the cross sections: (a) $(L / 2)$, (b) $(L / 4,3 L / 4)$, (c) $(L / 8,7 L / 8)$, (d) $(3 L / 8,5 L / 8)$, and (e) (ends $0, L)$.

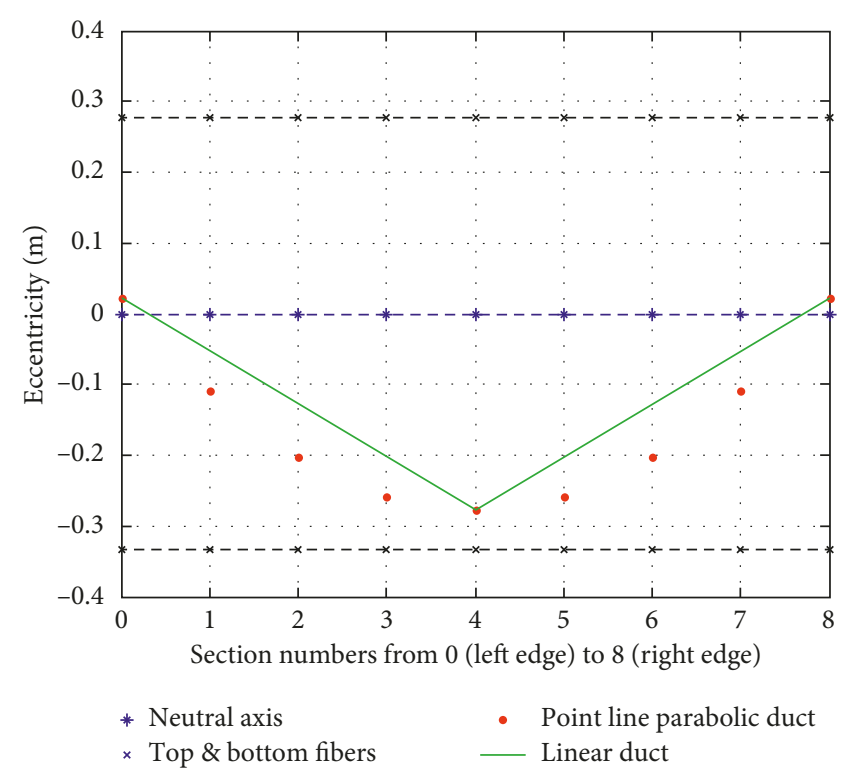

Figure 7: Ideal tendon profile based on the Magnel diagram of 9 cross sections each $L / 8$ apart.

profiles. It is shown that ideal parabolic and linear shape tendons and ducts, calculated by the formulas in this paper, are very close to the ideal and optimal tendon profile. It is recommended that both linear and parabolic ducts can be used by designers because they do not have any disadvantage. Moreover, the design is based on simple formulas without engaging with graphical work. It can also be implemented in design of continuous girders, assuming that the moments in intermediate pier supports are found by static calculations. Moreover, the blast load as a result of car bomb and so on can be considered and added to the service load. In this case, the relevant eccentricity and prestress level can be found as shown in the numerical example. This avoids the permanent deformation (Figure 2) as a result of explosion near the bridge.

As far as that author is aware, there is not any design method which is particularly suitable for design of accessible linear-type tendons and ducts in posttensioned beams. Instead, designers use traditional methods and increase the factor of safety to compensate lack of accuracy in modelling. Therefore, the method in this paper can be used for future design applications in which bridge design should be optimised to take an extra blast load as a result of explosion due to car bomb and so on. Moreover, in future by installing sensors in the open access box girder, compression conservation can be monitored and the validity of formulas in this paper can also be checked.

\section{Symbols}

A: $\quad$ Area of beam cross section

$0 \leq \alpha \leq 1$ : Prestress conservation in service

$e$ : $\quad$ Eccentricity

$e_{\mathrm{DM}}: \quad$ Design eccentricity in midspan

$e_{\mathrm{DC}}$ : Design eccentricity in supporting ends

$f_{\mathrm{tt}} \leq 0$ : Allowable transfer tensile stress 
$f_{\mathrm{tc}} \geq 0$ : Allowable transfer compressive stress

$f_{\text {st }} \leq 0$ : Allowable service tensile stress

$f_{\mathrm{sc}} \geq 0$ : Allowable service compressive stress

$i: \quad i$ th beam cross section

$L: \quad$ Beam length

$M_{t}: \quad$ Transfer bending moment

$M_{s}: \quad$ Service bending moment

$m: \quad$ Slope of the quadrilateral diagonals

$n: \quad$ Total number of beam cross sections

$P \geq 0: \quad$ Prestress compressive force

$W_{t}: \quad$ Load distribution in transfer

$W_{s}: \quad$ Load distribution in service

$x: \quad$ Location of the cross section

$Z_{t} \geq 0$ : Section modulus, top fibre

$Z_{b} \leq 0$ : Section modulus, bottom fibre.

\section{Conflicts of Interest}

The author declares that there are no conflicts of interest.

\section{References}

[1] D. Darwin, M. O’Reilly, J. Browning et al., "Multiple corrosion-protection systems for reinforced-concrete bridge components: laboratory tests," Journal of Materials in Civil Engineering, vol. 26, no. 11, Article ID 04014085, 2014.

[2] P. Wagner, "Advanced methods for the inside protection against corrosion and the accessibility of bridges with advanced box-girder design," Stahlbau, vol. 85, no. 2, pp. 86-111, 2016.

[3] H. Weiher and K. Zilch, "Usage of HD-PE in bridge construction-a corrosion protection system for steel tendons under extreme loading," in Proceedings of the Conference on Plastic Pipes XIII, Washington, DC, USA, October 2006.

[4] Pipes XIII, Washington, DC, USA, October 2006. "prestressing tendons in precast segmental bridges," PCI Journal, vol. 47, no. 5, pp. 76-91, 2002.

[5] Z. Hu, Y. Zhang, Z. Zeng, and L. Z. Sun, "Blast responses of bridge girders with consideration of isolation effect induced by car bomb," Journal of Engineering Material and Technology, vol. 139, no. 2, p. 021003, 2017.

[6] G. F. Kinney and K. J. Graham, Explosive Shocks in Air, Springer, New York, NY, USA, 1985.

[7] N. Krishna Raju, Prestressed Concrete, McGraw-Hill, New Delhi, India, 4th edition, 2006.

[8] R. I. Gilbert and N. C. Mickleborough, Design of Prestressed Concrete, Spon Press, London, UK, 1990.

[9] F. K. Kong and R. H. Evans, Reinforced and Prestressed Concrete, Chapman \& Hall, London, UK, 3rd edition, 1994.

[10] M. R. Ehsani and J. R. Blewitt, "Design curves for tendon profile in prestressed concrete beams," PCI Journal, vol. 31, no. 3, pp. 115-135, 1986.

[11] G. Magnel, Prestressed Concrete, Concrete Publication, London, UK, 1948.

[12] N. Krishnamurthy, "Magnel diagrams for prestressed concrete beams," Journal of Structural Engineering, vol. 109, no. 12, pp. 2761-2769, 1983.

[13] C. R. Calladine, “An improvement on Magnel's diagram and an application," Proceedings of the Institution of Civil Engineers, Structures and Buildings, vol. 159, no. 3, pp. 145-152, 2006.

[14] J. F. Stanton, "A simple sign convention for elastic analysis of prestressed concrete members," PCI Journal, vol. 52, no. 6, pp. 81-88, 2007. 


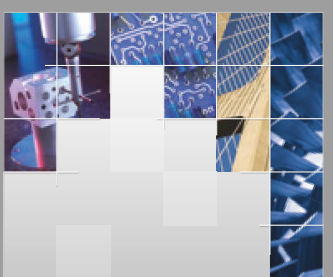

\section{Enfincering}
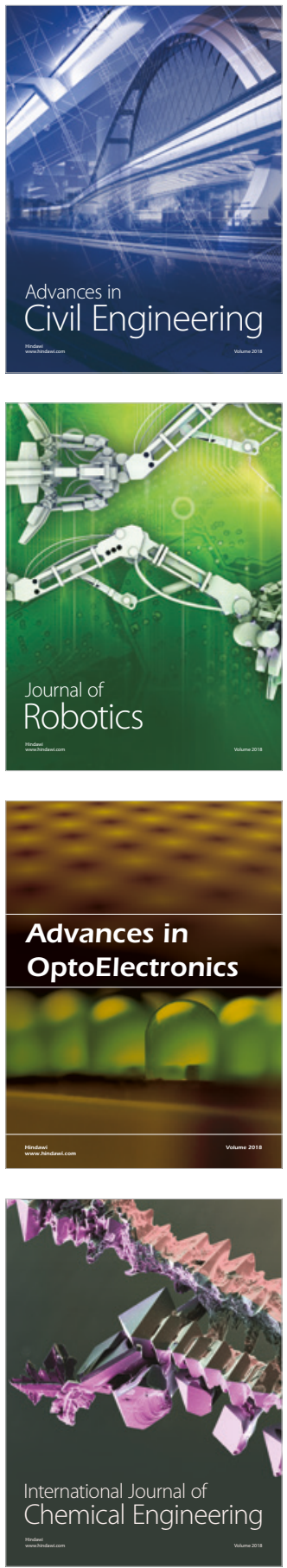

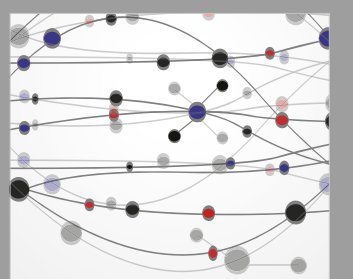

\section{Rotating \\ Machinery}

The Scientific World Journal

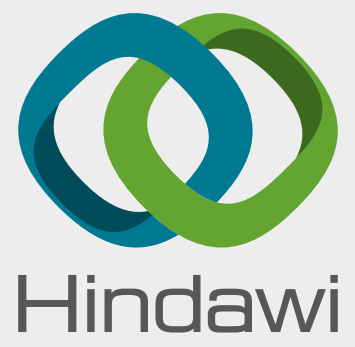

Submit your manuscripts at

www.hindawi.com
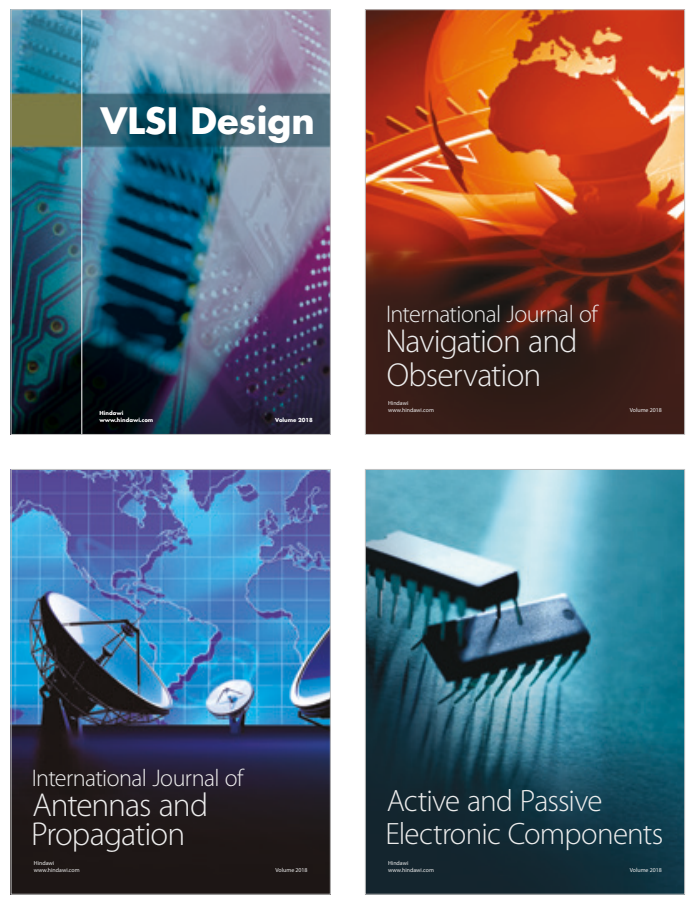
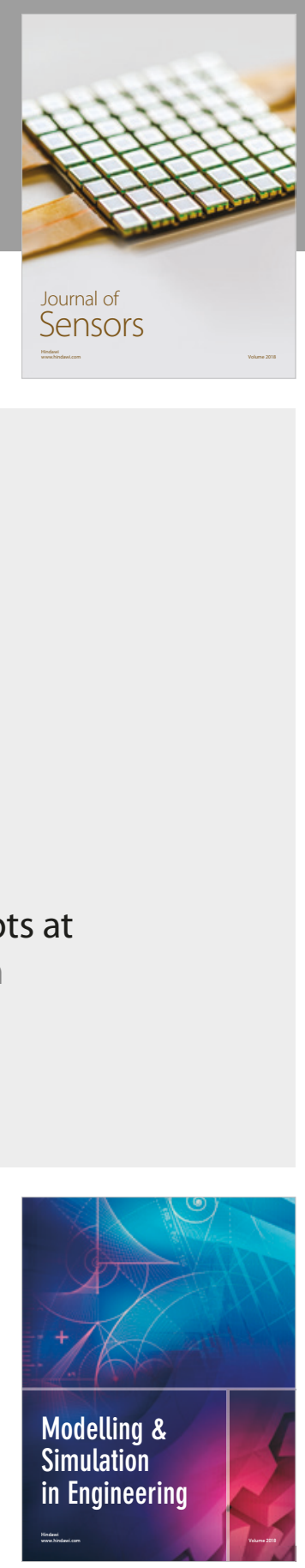

\section{Advances \\ Multimedia}
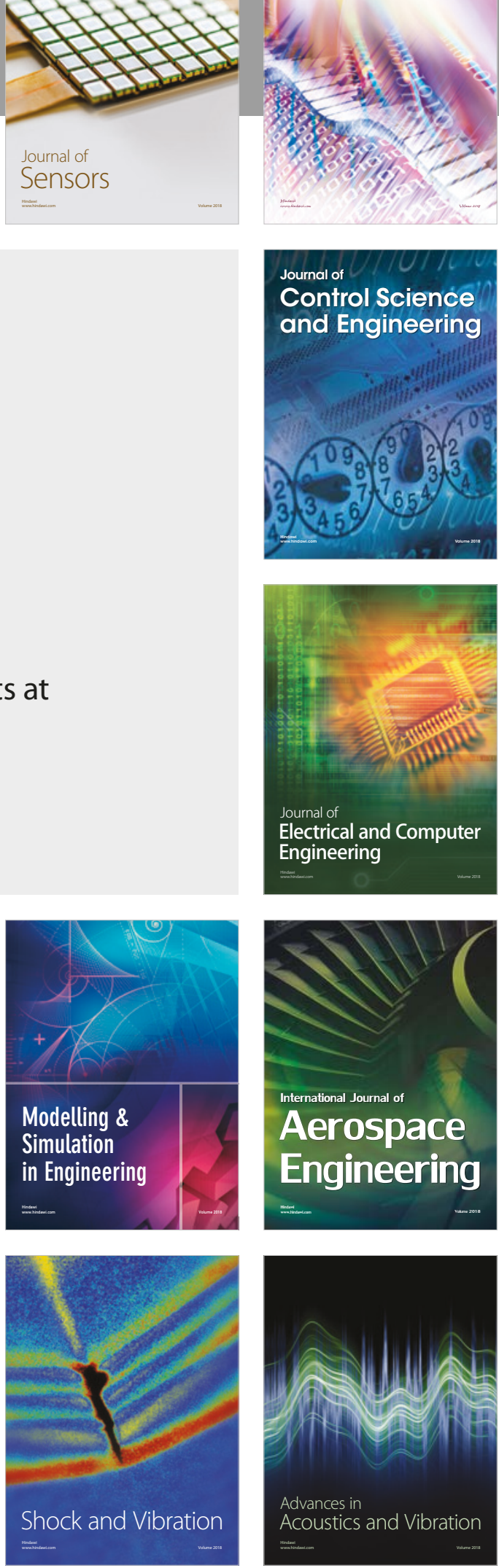